\title{
8 MANAGEMENT OF ALLERGY, RASHES, AND ITCHING
}

$T$ he vast majority of skin problems that present in the community are minor in nature. Unfortunately, very occasionally, the development of seemingly innocuous symptoms such as a rash and/or itching can be the presenting symptoms of a life threatening conditionnamely anaphylaxis or meningococcal septicaemia. While other clinical conditions can mimic both anaphylaxis and meningitis, especially in the early stages, there are usually clues in the presentation that help to minimise the delays in administering appropriate therapy. It is not possible in this article to cover all potential causes of a rash and/or itching. Rather, this chapter aims to focus on important conditions that require recognition, treatment, and possible referral in the acute prehospital setting. Box 1 lists the objectives of this article.

\section{Box 1 Article objectives}

With regard to the presentation of a rash and/or itching:

- To understand the basic physiology and pathology underlying allergic causes of rashes and itching

- To perform a primary survey of the patient and treat any immediately life threatening problems

- To identify any patients who have a normal primary survey but have an obvious need for hospital admission

- To perform a secondary survey incorporating other body systems that may be affected by a rash and/or itching

- To consider a list of differential diagnoses

- Discuss treatment based on the probable diagnosis(es)

- Discuss appropriate patient follow up

- Describe who can be safely considered for home treatment
See end of article for authors' affiliations

Correspondence to:

Dr M Langran, Aviemore

Health Centre, Muirton,

Aviemore PH22 1SY, UK;

mike@ski-injury.com

\section{BASIC PHYSIOLOGY AND PATHOLOGY UNDERLYING ALLERGIC CAUSES OF RASHES AND ITCHING}

Allergic reactions are linked to the release of chemical mediators, which are released from mast cells in a process known as degranulation. ${ }^{1}$ This occurs when an allergen cross links with immunoglobulin E (IgE) bound to receptors on mast cells. These chemicals are either released immediately (immediate allergic reaction), or after a few hours (late phase response). This timing helps to guide appropriate treatment.

\section{PRIMARY SURVEY}

Assess for an $\mathrm{ABC}$ problem in patients with itching and/or a rash (see box 2):

\section{Box 2 Primary survey}

Arrange immediate treatment and transfer to hospital if any of the following are present:

- Signs of airway obstruction

- Respiratory rate $<10$ or $>29$

- Oxygen saturation $<92 \%$ on air

- Pulse rate $<50$ or $>120$

- Systolic BP<90

- Glasgow coma score $<12$

The recognition of developing airway obstruction is critical, particularly in the presence of anaphylaxis. Patients may complain initially of a feeling of tightening in the throat, be unable to 
Table 1 Timing of release of chemical mediators and appropriate treatment

\begin{tabular}{lll}
\hline Timing of release & Examples & Treatment \\
\hline Immediate & $\begin{array}{l}\text { Histamine, tryptase, } \\
\text { hydrolases }\end{array}$ & $\begin{array}{l}\text { Antihistamines (for } \\
\text { example, } \\
\text { chlorpheniramine, } \\
\text { cetirizine) } \\
\text { Corticosteroids (for } \\
\text { example, prednisolone) }\end{array}$ \\
\hline
\end{tabular}

complete sentences, or have audible airway noise (stridor or wheeze). If airway obstruction becomes complete, then prompt initiation of a surgical airway will be required.

\section{PATIENTS WITH A NORMAL PRIMARY SURVEY WITH OBVIOUS NEED FOR HOSPITAL ADMISSION}

The following conditions may present initially with a normal primary survey but immediate treatment (if appropriate) and hospital admission should be initiated:

- Suspected rash of meningococcal septicaemia

- Definite exposure to a trigger that has previously lead to an anaphylactic reaction

- Self administration of adrenaline (epinephrine) by a patient for a suspected anaphylactic reaction

- A suspected anaphylactic reaction that has not fully developed

- Cellulitis-patient clinically toxic or affecting the periorbital tissues

The history and findings on examination should help to establish whether you are faced with such a scenario. Although these patients may not have abnormal clinical signs at the time of assessment, this should not lull you into a false sense of security as they may deteriorate rapidly. In the case of suspected meningococcal septicaemia, early administration of appropriate antibiotic therapy is safe and associated with an improved prognosis. ${ }^{2}$ Whenever there is a suspicion of anaphylaxis, adrenaline for intramuscular injection should be readily available. ${ }^{3}$ If the above situations present, based on the history and examination findings as described in this article, then appropriate treatment should be administered and hospital admission arranged.

\section{SECONDARY SURVEY (INCLUDING HISTORY TAKING)}

Having ensured that your patient has no immediately life threatening problems on their primary survey or the need for immediate hospital admission, you will be left with a patient for whom a careful history and examination should elucidate whether further treatment is required and whether or not the patient can be safely left at home. A history of the presenting complaint should be taken, any other information noted, and an examination performed as described earlier in this series. Remember that the skin is the largest organ in the body and adequate exposure may be required to permit a thorough examination to be completed. Obviously, the degree of exposure will be dictated by the prevailing circumstances and nature of the presenting complaint(s).

\section{HISTORY}

The following will be helpful in establishing the diagnosis in someone presenting with a rash or itching. Unfortunately,
Table 2 Potential triggers for anaphylaxis

\begin{tabular}{ll}
\hline Cause & Examples \\
\hline Foods & Nuts and seeds, eggs, seafood, kiwi fruit, bananas \\
Venom/stings & Bees, wasps, jellyfish, ants, snakebites \\
Drugs & $\begin{array}{l}\text { Antibiotics, aspirin/NSAIDs, vaccines, radio } \\
\text { contrast dye }\end{array}$ \\
Physical contacts & $\begin{array}{l}\text { Latex rubber } \\
\text { Other }\end{array}$ \\
\hline
\end{tabular}

NSAIDs, non-steroidal anti-inflammatory drugs (for example, ibuprofen, diclofenac, naproxen, etc)

there are few clinical tests that can help in the diagnostic process, which relies heavily on the use of a logical process to identify and eliminate serious problems.

\section{Onset of symptoms}

Did the symptoms come on suddenly over the course of a few minutes/hours or more gradually over the course of several days? Has there been recent injury to the area affected (especially a laceration)? Can symptoms be related to a particular event? In particular, the patient may be able to associate the symptoms with a specific trigger, for example, consumption of a particular meal, use of a new shampoo, etc. Table 2 lists the common potential triggers for an anaphylactic reaction.

\section{Piffall}

Nuts are increasingly being used as a "filler" in a wide range of foods. The patient may not therefore be aware that they have consumed nut products

\section{Rash/swelling}

If a rash is present then is it localised or generalised? What colour is the rash? Does the area of the rash itself itch or is it actually painful to touch? Does the rash change colour when pressed against the edge of a glass? If swelling is present, which part(s) of the body are affected? Pay particular heed to any swelling involving the mouth, tongue, or eyes.

\section{Associated symptoms}

Of utmost importance is whether the patient feels generally well in him/herself. Does the patient have a generalised itch all over? Is there disturbance of another bodily system-for example, gastrointestinal upset? Specific inquiry should be made about the presence of vomiting, headache, neck pain, cough, and eye discomfort. The patient should be asked whether they have recently had an upper respiratory tract infection, or tonsillitis, or both.

\section{Progress of symptoms}

It is important to ascertain whether the symptoms have continued to worsen since their onset. Anaphylaxis and meningococcal septicaemia are progressive conditions that will steadily deteriorate with time. However, if a patient with an allergic reaction but without signs of anaphylaxis has remained stable for more than an hour they are unlikely to deteriorate further.

\section{Previous episodes}

Ask whether a similar episode has affected the patient before. Previous episodes of anaphylaxis are unlikely to be easily 
forgotten! Unfortunately, a history of a previous allergic reaction (mild or severe) does not predict the likelihood of an anaphylactic reaction-a reaction can still occur despite a long history of previous safe exposure. ${ }^{4}$ temperature and/or the presence of enlarged (and often painful) lymph glands in the submandibular and/or cervical regions suggest the possibility of an infective process. It is sensible to test for neck stiffness in any patient who presents with a rash and systemic upset. The patient's neck should be passively flexed forwards towards the chest wall, a manoeuvre that should not be painful to complete. If neck flexion causes pain, then Kernig's and Brudzinski's signs should be tested.

- Kernig's sign-extend the knee with the hip flexed. Positive test if hamstrings contraction occurs as a result

- Brudzinski's sign-flex the neck passively. Test is positive if the knees and hips flex as a result.

\section{珨 Pitfall}

Exposure to certain triggers is associated with an increased incidence of allergic reactions (table 2).

\section{Medical history/drug history}

Any history of similar events should be noted. Many drugs can be implicated in the development of allergic reactions and anaphylaxis. Aspirin accounts for about 3\% of anaphylactic reactions and symptoms may occur hours after ingestion. ${ }^{5}$ Those allergic to aspirin may also be sensitive to NSAIDs, which may cause a similar reaction. A similar allergic association can occur with penicillins and cephalosporins. Even people who have had no previous problems with penicillins may experience an anaphylactoid reaction after taking them. Diabetics are at a higher risk of cellulitis.

\section{Family history}

A positive family history of similar episodes suggests hereditary angio-neurotic edema (HANE), which is inherited as an autosomal dominant trait.

\section{Social history}

Has the patient been in contact with anyone who has had similar symptoms or felt unwell? Is the patient worried about a particular diagnosis? If so, this should be excluded if possible so that the patient may be reassured.

\section{Examination}

See the earlier article in this series relating to patient examination. It is always advisable to check and record the vital signs of any patient who presents with a possible allergic reaction or rash. This includes the measurement of temperature, pulse, blood pressure, and respiratory rate. An increased
Although a positive response to Kernig's or Brudzinski's tests is diagnostic of meninigism, the absence of a positive response does not rule out meningitis

\section{General examination}

Note the patient's overall demeanour. Do they appear well, at ease, and able to converse normally or are they anxious, sweaty, confused, or making abnormal noises as they breathe? If this is the case, go back and reassess their primary survey and consider whether further treatment and/ or onward referral are required.

\section{Examination of the skin}

As previously mentioned, it is important to ensure adequate exposure of the skin, especially in younger children who may be less able or likely to bring the presence of a rash to your attention. In a significant proportion of patients with meningococcal septicaemia, the rash starts on the palms of the hands and/or the soles of the feet so be sure to examine these carefully. Is the rash painful to the touch? Record any swelling of the tissues, especially around the face and the eyes. Gently examine inside the mouth looking for swelling of the tongue. Note the presence of any scratch marks on the body. Note the colour associated with any rash-does the rash disappear or change colour when pressure is applied? (Ideally this should be done with the base of a clear glass). Table 3 lists the common terms used to describe physical changes in the skin associated with the presence of a rash.

\begin{tabular}{|c|c|c|}
\hline Terminology & Description & Clinical examples \\
\hline Macular & $\begin{array}{l}\text { Non-infiltrated flat lesions which differ } \\
\text { in colour from adjacent areas of skin }\end{array}$ & Erythema, purpura \\
\hline Papular & $\begin{array}{l}\text { Well demarcated raised lesions in the skin } \\
\text { of varying sizes }\end{array}$ & Urticarial wheals, planar warts \\
\hline Vesicular & $\begin{array}{l}\text { Small protuberances with a central cavity } \\
\text { containing clear liquid }\end{array}$ & Chickenpox \\
\hline \multirow[t]{3}{*}{$\begin{array}{l}\text { Excoriations } \\
\text { Purpura }\end{array}$} & $\begin{array}{l}\text { Very superficial wounds in the surface of the skin } \\
\text { Small patches of non-blanching discolouration } \\
\text { caused by bleeding from small superficial } \\
\text { blood vessels in the skin }\end{array}$ & $\begin{array}{l}\text { Scratches } \\
\text { Meningococcal disease }\end{array}$ \\
\hline & Petechiae - small spots of purpura & $\begin{array}{l}\text { Idiopathic thrombocytopaenic purpura } \\
\text { (ITP) }\end{array}$ \\
\hline & Ecchymoses-large confluent patches of purpura & Henoch Schonlein purpura (HSP) \\
\hline
\end{tabular}




\section{䔾 Pitfall}

Although a non-blanching purpuric rash should be considered to be indicative of meningococcal septicaemia in the prehospital setting, neither the absence of a rash nor the fact that a rash blanches should be considered as ruling out meningitis or septicaemia

\section{Investigations}

There are few investigations that will quickly confirm the diagnosis of a rash or itching in the acute prehospital setting. The diagnosis usually requires a clinical interpretation of the symptoms and signs presented.

\section{Differential diagnosis}

Table 4 lists the main important conditions to be distinguished in a patient presenting with a rash and/or itching. Further information is given later in this article specific to each condition.

\section{Management plan}

Depending on the suspected diagnosis and clinical condition of the patient, the usual management plan can be summarised as one of the following four choices

- Plan 1-admit and treat immediately as an emergency

- Plan 2-admit as a semi-urgent case for further assessment and treatment

- Plan 3-advisable to seek further advice from hospital

- Plan 4-can be treated at home, assuming no features of concern

Where indicated, appropriate home management options are discussed for each condition

Table 4 The main important conditions to be distinguished in a patient presenting with a rash and/or itching

\begin{tabular}{ll}
\hline Rash+/-itch & Itching alone \\
\hline Immune system mediated & Immune system mediated \\
Anaphylaxis & Anaphylaxis \\
Anaphylactoid reaction & Anaphylactoid reaction \\
Allergic reaction-local & Systemic \\
Urticaria ("hives") and/or & Systemic upset (for example, \\
angioedema & uraemia, cholestasis, blood \\
Idiopathic thrombocytopaenic & disorders) \\
purpura (ITP) & Other \\
Infective & Senile itch \\
Bacterial & Solid tumours \\
Meningococcal septicaemia & HIV \\
Celllulitis & \\
Impetigo & \\
Scarlet fever & \\
Viral & \\
Varicella zoster & \\
Primary infection (chickenpox) & \\
Reactivation (herpes zoster or & \\
"shingles") & \\
Measles & \\
Rubella (German measles) & \\
Non-specific viral rash & \\
Other conditions & \\
Henoch Schonlein purpura & \\
Psoriasis & \\
Eczema & \\
\hline
\end{tabular}

IMMUNE SYSTEM MEDIATED CONDITIONS Anaphylaxis and anaphylactoid reactions

- Management plan-1. Admit and treat immediately Anaphylaxis refers to a severe generalised allergic reaction, whereby specific triggers (for example, insect stings, peanuts) stimulate the release of IgE immunoglobulin. This IgE release causes vasodilatation, airway swelling, and capillary leakage leading to hypotension. An anaphylactoid reaction results in an identical situation, but does not entail the release of IgE. An example of this is the reaction that can be seen to radiography dye. ${ }^{6}$ While no universally accepted definition exists, a good working definition is "a severe allergic reaction to any stimulus, (usually) having sudden onset and generally lasting less than 24 hours, involving one or more body systems and producing one or more symptoms such as hives, flushing, itching, angio-oedema, stridor, wheezing, shortness of breath, vomiting, diarrhoea or shock". ${ }^{7}$ The rate of anaphylaxis in the UK has risen from 6 per million in 1990/ 91 to 41 per million in $2000 / 01 .^{8}$

\section{Symptoms and signs of anaphylaxis}

The diagnosis of anaphylaxis is clinical. Symptoms usually begin within minutes of exposure to the trigger(s), but may be delayed by several hours. Many of the symptoms and signs of anaphylaxis may mimic other clinical conditions, thus leading to a delay in diagnosis (table 5). For this reason, the first attack is particularly dangerous. Having experienced the symptoms once, a surviving patient is likely to recognise their occurrence in the future thus aiding earlier diagnosis and treatment. Over $90 \%$ of patients with anaphylaxis will develop cutaneous symptoms such as urticaria (see later), itching, and angio-oedema that can help to distinguish the condition from other diagnoses. A vasovagal reaction, perhaps the commonest mimic of an anaphylactic episode, does not involve cutaneous changes, tachycardia, or bronchospasm. Patients often describe a non-specific but frightening feeling of "impending doom". Untreated, anaphylaxis will steadily worsen and a progressive deterioration in the patient's clinical condition should alert an observer to the possibility of this diagnosis. Patients with significant cardiovascular collapse may be unable to give a coherent history, adding to the potential for diagnostic delay.

Table 5 Symptoms and signs of anaphylaxis with differential diagnosis(es)

\begin{tabular}{|c|c|}
\hline $\begin{array}{l}\text { Symptom/signs of } \\
\text { anaphylaxis }\end{array}$ & Differential diagnosis(es) \\
\hline $\begin{array}{l}\text { Respiratory compromise } \\
\text { (shortness of breath, } \\
\text { wheeze, stridor) }\end{array}$ & $\begin{array}{l}\text { Asthma, COPD, inhaled foreign body, } \\
\text { pulmonary embolism }\end{array}$ \\
\hline Loss of consciousness (LOC) & $\begin{array}{l}\text { Vasovagal reaction, seizures, cardiac } \\
\text { event (for example, arrhythmia) }\end{array}$ \\
\hline Hypotension & $\begin{array}{l}\text { Vasovagal reaction, shock (cardiogenic/ } \\
\text { septic/hypovolaemic) }\end{array}$ \\
\hline Collapse & $\begin{array}{l}\text { As for hypotension/LOC plus panic } \\
\text { attack, hyperventilation syndrome, } \\
\text { Munchausen's syndrome }\end{array}$ \\
\hline Cutaneous skin flushing & $\begin{array}{l}\text { Vasovagal reaction, carcinoid syndrome, } \\
\text { postmenopausal flushing }\end{array}$ \\
\hline $\begin{array}{l}\text { Gastrointestinal (diarrhoea, } \\
\text { abdominal cramps, nausea, } \\
\text { and vomiting) }\end{array}$ & $\begin{array}{l}\text { Hereditary angio-neurotic oedema } \\
\text { (HANE), food poisoning }\end{array}$ \\
\hline
\end{tabular}


Consider when compatible history of severe allergic-type reaction with respiratory difficulty and/or hypotension especially if skin changes present

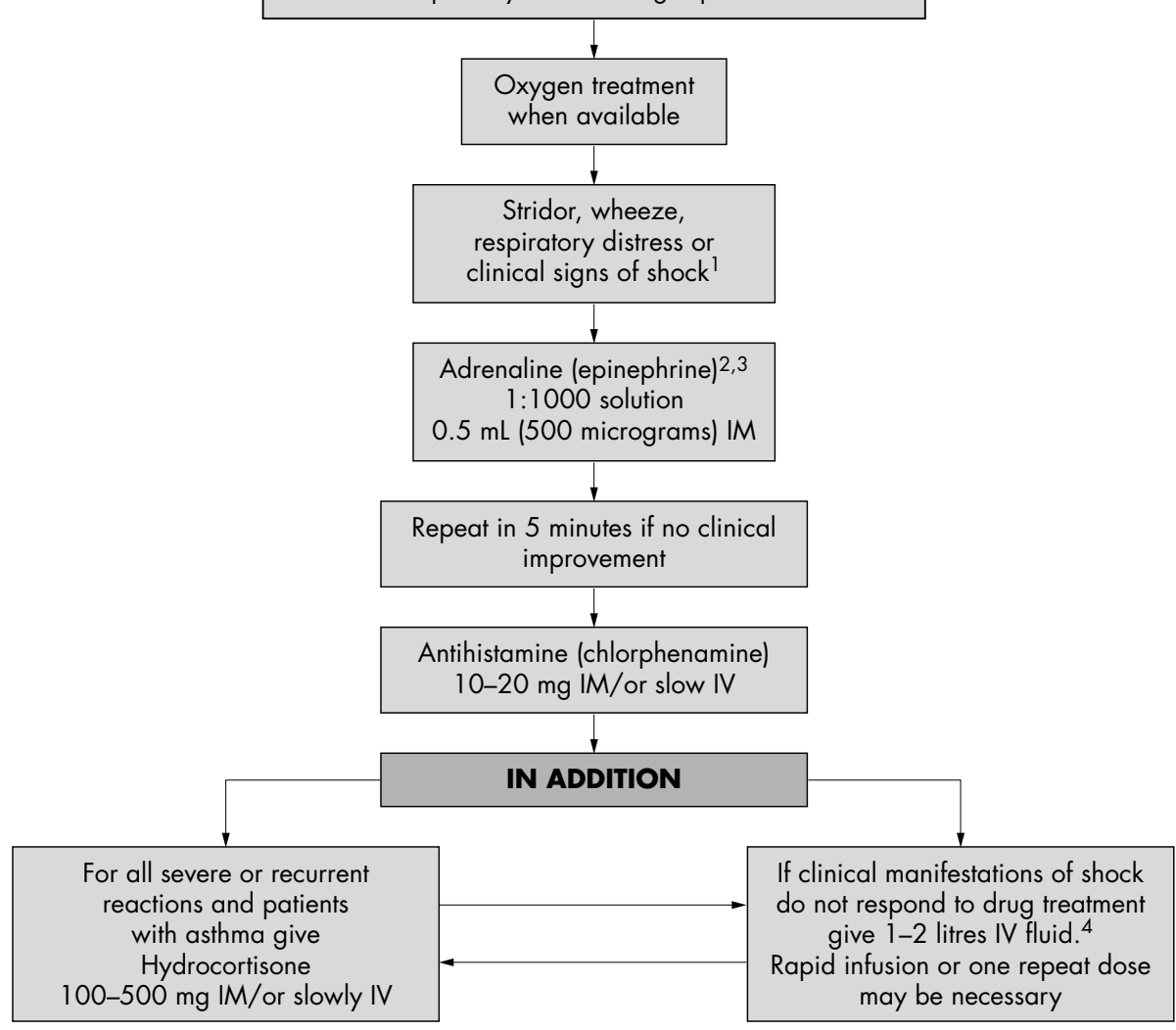

Figure 1 Anaphylactic reactions: treatment algorithm for adults by first medical responders (reproduced with permission of the Resuscitation Council UK http://www.resus.org.uk/pages).

\section{Management of anaphylaxis}

The management of suspected anaphylaxis is a medical emergency and is summarised in figures 1 and 2 .

Early recognition of symptoms, removal of the triggering source (if possible), and prompt administration of adrenaline (epinephrine) are the fundamentals of successful management.

\section{$A B C s$}

Airway patency must be maintained and $100 \%$ oxygen should be applied to all patients as soon as it is available. If the patient has developed signs of complete airway obstruction then a surgical airway must be initiated. Intravenous access should be established as large volumes of fluid may be required to treat the severe hypotension often seen in anaphylaxis, if it does not correct rapidly with drug treatment. A rapid infusion of 1-2 litres of crystalloid or colloid, given in 250-500 ml boluses, may be required if the radial pulse is lost. Children should receive an initial bolus of $20 \mathrm{ml} / \mathrm{kg}$ with boluses repeated until a response is noted.

\section{Adrenaline}

Adrenaline $0.5 \mathrm{mg}(0.5 \mathrm{ml}$ of $1: 1000)$ should be injected intramuscularly, preferably into the antero-lateral aspect of the upper arm or thigh. This route of administration has been shown to be superior to subcutaneous injection. ${ }^{9}$ Adrenaline should be re-administered every five minutes until clinical improvement occurs. People taking $\beta$ blockers may have a suboptimal response to adrenaline, with possible persistent severe hypotension and bradycardia. ${ }^{10}$ The latter can be treated with atropine (0.3-0.5 mg intramuscularly every 10 minutes to a maximum of $2 \mathrm{mg}$ ). Glucagon (as a $1 \mathrm{mg}$ intravenously bolus) may also be effective for patients taking $\beta$ blockers although it is not licensed for this indication. ${ }^{6}{ }^{10}$

\section{Antihistamines}

Histamine is one of the prime chemical mediators of the anaphylactic reaction. Antihistamine drugs may therefore provide rapid relief of distressing symptoms. $\mathrm{A} \mathrm{H}_{1}$ antagonist drug such as chlorpheniramine (10-20 mg intramuscularly or slow intravenously) may be combined with a $\mathrm{H}_{2}$ antagonist such as ranitidine ( $150 \mathrm{mg}$ orally, if able to take) to effect maximal histamine block. ${ }^{11}$

\section{Corticosteroids}

Corticosteroids, in the form of hydrocortisone $200 \mathrm{mg}$ (intravenously or intramuscularly) or prednisolone (oral) $50 \mathrm{mg}$ should be administered to minimise the likelihood and severity of second phase reactions. The benefits of administering corticosteroids can take 6-12 hours to be realised, and it is emphasised that their main therapeutic influence is upon recurrent or protracted episodes. Even so, it is recognised that patients who have received corticosteroids may still develop severe biphasic or prolonged reactions. ${ }^{12}{ }^{13}$

\section{Pitfall}

Rapid administration of intravenous chlorpheniramine or corticosteroids can cause hypotension 
Consider diagnosis of anaphylaxis when compatible history of severe allergic-type reaction with respiratory difficulty and/or hypotension especially if skin changes present

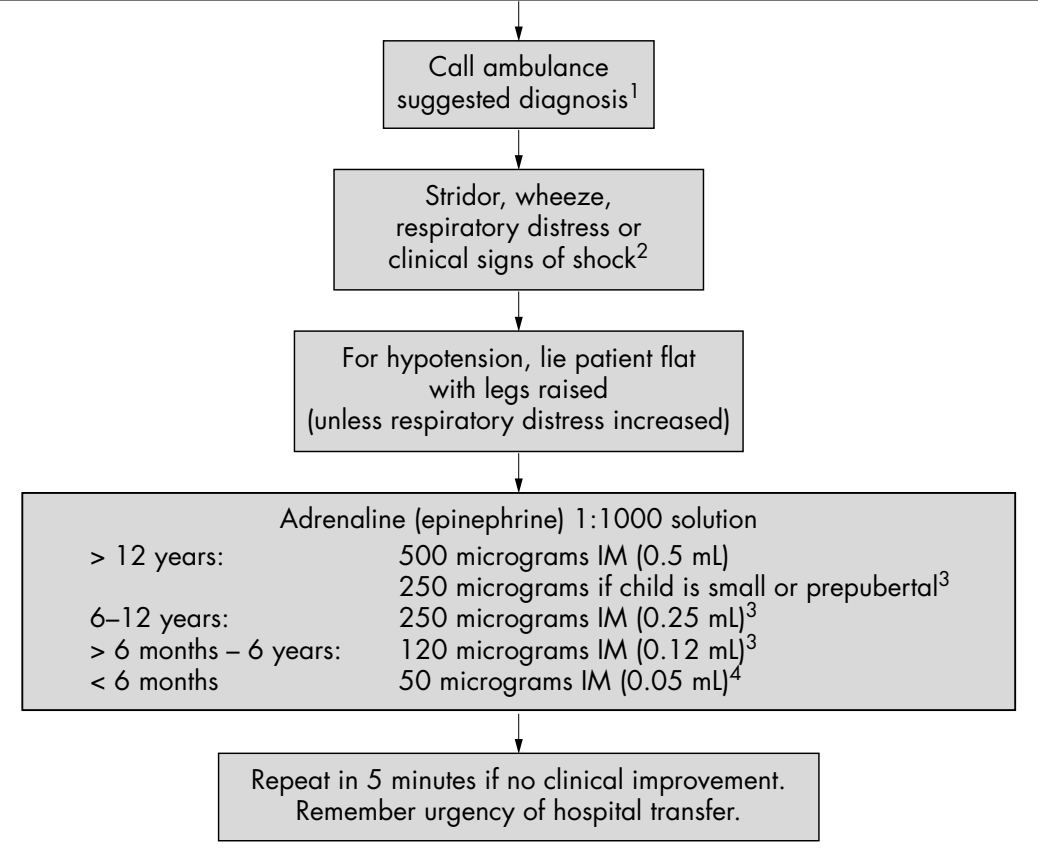

Figure 2 Anaphylactic reactions: treatment algorithm for children in the community (reproduced with permission of the Resuscitation Council UK http:// www.resus.org.uk/pages).

\section{$\beta_{2}$ agonists}

Bronchospasm is often a prominent symptom of anaphylaxis and commonly manifests itself as shortness of breath and/or wheezing. It should be treated with a $\beta_{2}$ agonist such as salbutamol (Ventolin) or terbutaline (Bricanyl). Depending on resources available, these may be administered via a standard inhaler device or through a nebuliser (oxygen driven if possible). $\beta_{2}$ agonist therapy can be repeated as required or given continuously en route to hospital according to the degree of response achieved.

\section{给 Pitfall}

Bronchospasm should improve with the administration of a $\beta_{2}$ agonist, but this does not mean that the anaphylactic process is resolving or that adrenaline is not required

\section{Admission to hospital}

Although most episodes of anaphylaxis will occur and recover within one to eight hours, the potential for a second phase reaction remains. As a consequence, all patients who have sustained an anaphylactic reaction should be observed and monitored in a hospital setting. Local hospital policies may vary, but second phase reactions can occur up to 24 hours after the initial episode, regardless of the response to treatment. ${ }^{10}{ }^{14}$ For the next 48 hours after discharge, it is recommended that the patient remains in an environment that permits easy access to medical attention should symptoms recur. This has important implications for those patients who live in isolated rural communities.
Follow up arrangements

After an episode of anaphylaxis, there are two important issues to address with the patient. Firstly, an attempt should be made to identify the precipitating cause and reduce the likelihood of further exposure. The possible cause may be obvious from the original clinical presentation or otherwise confirmation requires referral to an allergist for a skin prick test. Those who subsequently have a confirmed IgE mediated allergy may be amenable to specific and potentially curative immunotherapy. Secondly, patients need to be aware of the correct actions in the event of a recurrence. They should be prescribed a self injection device for the administration of adrenaline (for example, Epi-Pen), be instructed in its appropriate use, and advised to obtain a Medic-Alert bracelet or necklace. Close relatives, friends, and/or neighbours should also be considered for education as deemed appropriate to the individual circumstance.

\section{Allergic reactions - local}

A far more common occurrence than anaphylaxis is the development of a localised reaction to an allergen without the development of serious generalised symptoms. The reaction seen after an insect bite (see fig 3) is a classic example of this. There is usually (but not always) a history of exposure to a potential allergen, after which the patient may notice the development of skin changes such as rash, itching, swelling, and/or pain. If the affected area involves the mouth or neck then the potential for airway compromise must be considered. There are three simple but important differentiations to be made that help to distinguish these less serious local reactions from those that may lead to a patient's deterioration: 


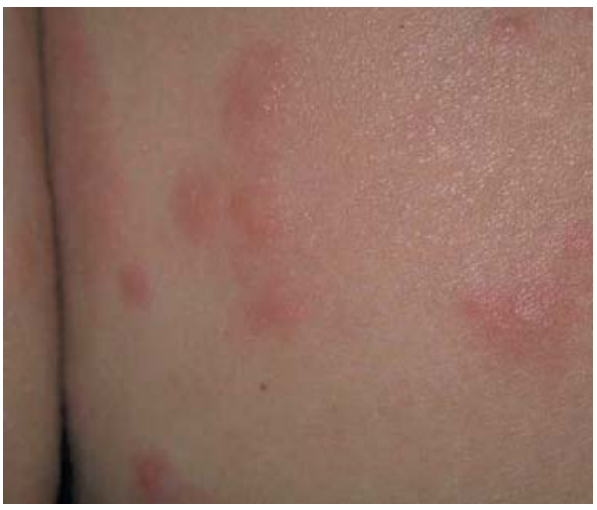

Figure 3 Rash caused by an insect bite. Reproduced with permission from Dermatology Online Atlas (http://www.dermis.net).

- The patient's symptoms are generally localised to the affected area

- The patient has no symptoms or signs of systemic upset

- The patient's symptoms do not progressively worsen

\section{Treatment}

Simple measures such as the application of ice may help with swelling and pain. The use of an oral antihistamine such as cetirizine (which can be bought over the counter by the patient and used in patients from the age of 2 upwards) will alleviate most of the patient's symptoms within one to three days. If the reaction is more severe, then a three day course of oral corticosteroids, for example, prednisolone EC $(1 \mathrm{mg} / \mathrm{kg} / \mathrm{d}$ for children, $30 \mathrm{mg} / \mathrm{d}$ for adults) may be administered to help reduce the reaction. The patient should be advised to seek medical attention again if their symptoms worsen, become generalised, or have not resolved after three days.

\section{Urticaria ("hives") and angio-oedema}

- Management plan 4. Home management if no features of concern

Urticaria and angio-oedema are related conditions and occur together in about $50 \%$ of cases, with urticaria a single entity in $40 \%$ and the remaining $10 \%$ being angio-oedema alone. The British Association of Dermatologists offers useful online information for both patients and doctors. ${ }^{15}$

\section{Simple urticaria}

This condition typically produces an itchy "wheal and flare" reaction anywhere on the body. The lesions usually have a raised central area and blanch on direct pressure (see figs 4 and 5).

\section{Angio-oedema and urticaria}

This condition, which is more common in female patients, tends to affect the extremities (for example, lips, eyelids, and digits) and is often painful rather than itchy. Most episodes are acute and self limiting but up to $10 \%$ will become chronic in nature. In most cases, no definite causal agent is found although any of the substances in table 2 may be implicated in some cases. Most symptoms will settle by six weeks and the patient can be reassured about the benign nature of the condition. Treatment in the acute phase entails avoidance of any obvious trigger(s) and the use of an oral $\mathrm{H}_{1}$

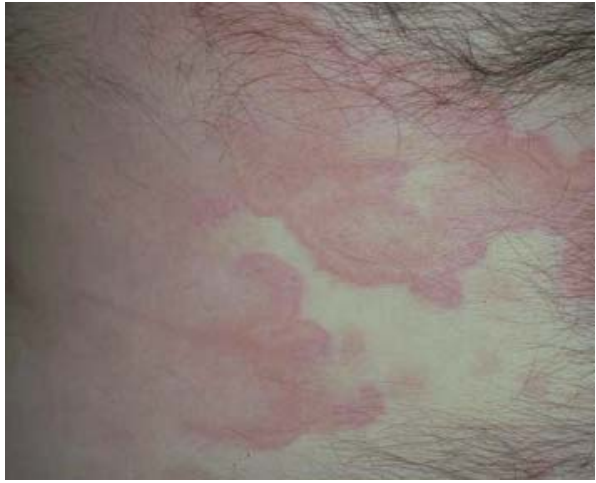

Figure 4 Rash caused by hives. Reproduced with permission from Dermatology Online Atlas (http://www.dermis.net).

antihistamine agent such as chlorpheniramine or cetirizine. In the event that one agent is ineffective, another should be substituted. ${ }^{16}$ In the longer term, other agents including oral corticosteroids may be required if the condition becomes chronic.

\section{Angio-oedema without urticaria}

The commonest cause of isolated angio-oedema is hereditary angio-neurotic edema (HANE) - this condition is characterised by recurrent acute swelling affecting the cutaneous tissues and mucous membranes of any part of the body. Most patients inherit the condition as an autosomal dominant gene and experience their first episode in childhood. The defect is a lack of $C^{\prime} 1$ esterase inhibitor protein that leads to inappropriate activation of the complement pathway. Triggers may include allergens but a reaction can also occur after fright or physical trauma. Patients are usually familiar with the pattern of their symptoms, which makes the diagnosis easier as their experience grows. Although the symptoms of swelling usually develop gradually over many

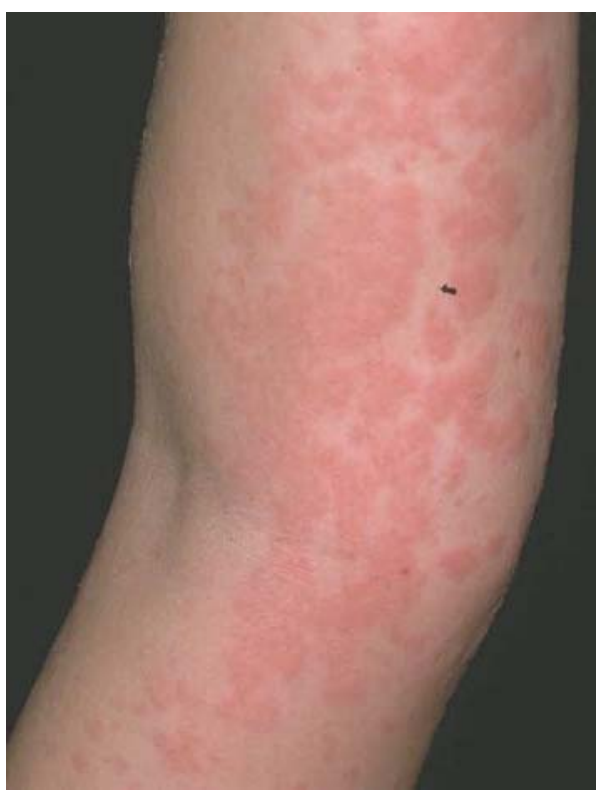

Figure 5 Rash on the leg caused by uticaria. Reproduced with permission from Dermatology Online Atlas (http://www.dermis.net). 
hours, involvement of the upper airway tissues can cause concern. Management of an acute episode depends on its severity. While peripheral swelling does not require active treatment, airway involvement requires active management including the administration of $\mathrm{C}^{\prime} 1$ inhibitor concentrate. ${ }^{17}$ Some patients may carry an auto-injector containing this drug, which should be administered immediately if available. Otherwise, urgent transfer to an alerted hospital is indicated.

Other causes of isolated angio-oedema may be linked to the use of certain medications (ACE inhibitors in particular). Angiotension $_{2}$ receptor antagonists (for example, losartan) can be substituted as these are not associated with the condition. If no cause can be identified, the condition is deemed to be idiopathic.

\section{Idiopathic thrombocytopaenic purpura (ITP)}

- Management plan 3. Seek further advice from hospital This is a condition where the body's immune system attacks platelets, the blood cells that help form blood clots. This leads to a low platelet count in the blood (detected through a full blood count). As a result, ITP causes small amounts of bleeding into the skin tissues. Its cause is unknown, but there are two forms-one that affects children (usually between 2-4 years old and commonly after a viral infection) and one that affects adults (usually women). It results in a non-blanching purpuric rash, sometimes with more extensive patches of bruising, but is not acutely life threatening. Usually, people with ITP show no other signs of illness other than their rash-in contrast with patients with meningococcal disease. If in doubt as to the cause of purpura in the prehospital setting, further medical advice should be obtained or hospital admission arranged.

\section{INFECTIVE CONDITIONS \\ (1) Bacterial \\ Meningococcal septicaemia}

- Management plan 1. Admit and treat immediately

Meningococcal septicaemia is a life threatening condition with high morbidity and mortality. In 2003, 732 cases were reported in England and Wales. ${ }^{18}$ Unfortunately, particularly in its early stages, its symptoms are fairly nonspecific and may mimic those of a common viral illness. Although it may not occur at all, the development of a rash is an important clinical sign, especially in the presence of systemic upset (for example, headache, vomiting and/or altered mental status). The Meningitis Research Foundation (http://www.meningitis.org.uk) is one of many resources with practical advice and information for health professionals and lay persons.

The classic rash of meningococcal septicaemia (see fig 6) may consist of any of the following:

- Tiny red or brown pin prick marks (petechiae)

- Purple blotches

- Blood blisters

The rash is usually described as "non-blanching" - that is, if a glass tumbler is pressed firmly against a septicaemic rash, the marks will not fade. In its initial phase, the rash may not have any of the classic features described. In the case of any patient with a rash, the patient and/or their carers should be educated about features of possible concern and advised to
Table 6 Recommended drug doses for meningococcal septicaemia

\begin{tabular}{lll}
\hline Patient's age & Penicillin V & Ceftriaxone \\
\hline Infant & $300 \mathrm{mg}$ & $100 \mathrm{mg} / \mathrm{kg}$ \\
Child (1-9 years) & $600 \mathrm{mg}$ & $1 \mathrm{~g}$ \\
Child (10 yearst) & $1.2 \mathrm{~g}$ & $1 \mathrm{~g}$ \\
Adult (16 years + ) & $1.2 \mathrm{~g}$ & \\
\hline
\end{tabular}

seek advice again if the nature of the rash changes. It often starts first on the sole of the feet or the palm of the hands. The rash may not be as distinct in patients with darkly coloured skin, in whom areas such as the conjunctiva and the roof of the mouth should be checked carefully. Patients with septicaemia will usually become seriously ill, often within a short time frame. Symptoms may be very subtle in infants and may include irritability, poor feeding, weak cry, and mottled skin. If in doubt, the infant should be admitted for observation. In the case of suspected meningococcal septicaemia, appropriate antibiotic treatment should be administered as soon as possible. Prehospital antibiotic administration has been shown to reduce the mortality in meningococcal meningitis by about $50 \%$. The incidence of true anaphylactic reactions to penicillin is extremely low and treatment should not be delayed unless there is a clear personal history of such. ${ }^{19}$ In these circumstances, ceftriaxone is the preferred alternative. ${ }^{20}$ Table 6 gives the recommended doses of each drug.

\section{Cellulitis}

- Management plan-2 (admit semi-urgently) or 4 (treat at home). Depending on severity

Cellulitis is an acute bacterial infection of the skin and subcutaneous tissues. Most commonly it involves the lower leg although any part of the body may be affected. Untreated, infection can spread and lead to septicaemia. Cellulitis involving the peri-orbital or orbital areas is of particular concern as infection may spread to the sagittal sinuses. The commonest clinical sign initially is a hot, raised, and erythematosus area of skin that is tender to the touch (see fig 7). As the cellulitis develops, the patient may develop systemic signs of infection (raised temperature, sweats, tachycardia, and a feeling of malaise). The usual organisms involved are haemolytic streptococci and staphylococcus aureus. ${ }^{21}$ The history may indicate the portal of entry for

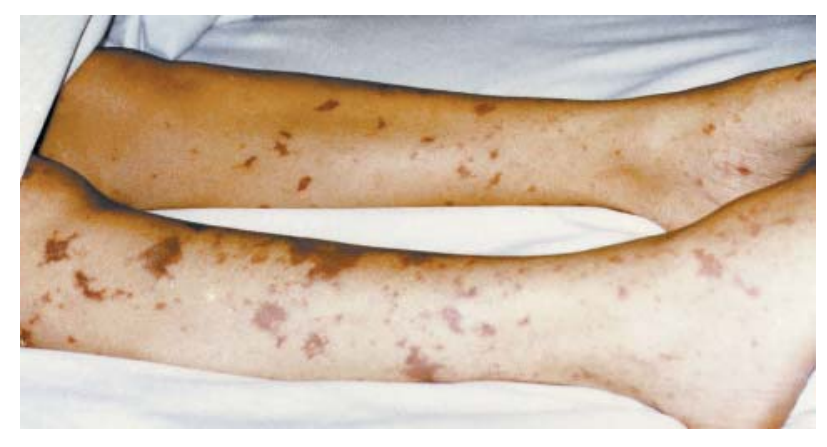

Figure 6 Rash caused by septicaemia. Reproduced with permission from The Meningitis Trust (http://www.meningitis-trust.org). 
the bacteria such as a laceration, abrasion, or recent surgery. The mainstay of treatment is a combination of antibiotic therapy, analgesia, elevation of affected limbs, and treatment of any underlying condition.

\section{Antibiotic therapy}

The standard antibiotic combination for cellulitis is benzyl penicillin and flucloxacillin (both $500 \mathrm{mg}$ six hourly for adults-see the BNF or MIMS for paediatric dosing). An alternative for those hypersensitive to penicillin is erythromycin 500 mg six hourly. Hospital admission for intravenous antibiotics is recommended for patients with involvement of the (peri)orbital tissues, systemic symptoms, and those unable to tolerate oral treatment.

\section{Analgesia}

Cellulitis is often painful. Adequate analgesia should be prescribed and the patient advised on minimising friction pain from clothes touching the affected area.

\section{Elevation}

An important aspect of management is to keep the affected limb elevated whenever possible. This helps to reduce tissue swelling and pain. Ideally the affected limb should be kept higher than the heart and gentle exercises promoted to encourage fluid movement and reduce the incidence of complications such as deep vein thrombosis and pressure ulceration.

\section{Treatment of the underlying condition}

Any obvious wound that may have acted as a portal of entry should be examined and treated appropriately. Embedded foreign bodies should be removed. Other predisposing factors include diabetes, pre-existing oedema or skin ulceration, and vascular disease. Cellulitis resulting from a human or animal bite can involve multiple organisms. Wounds should be thoroughly cleaned and a wide spectrum antibiotic such as co-amoxiclav prescribed.

\section{Impetigo}

- Management plan-4. Treat at home

Impetigo is a highly contagious bacterial infection of the superficial tissues of the skin. It is spread by direct contact and is common among children. The most commonly implicated organisms are Staphylococcus aureus and group A $\beta$ haemolytic streptococcus. Although healthy skin can be affected, these bacteria usually enter the skin through a cut, scratch, or abrasion. The nose and peri-oral regions, being susceptible to minor trauma, are the usual sites of

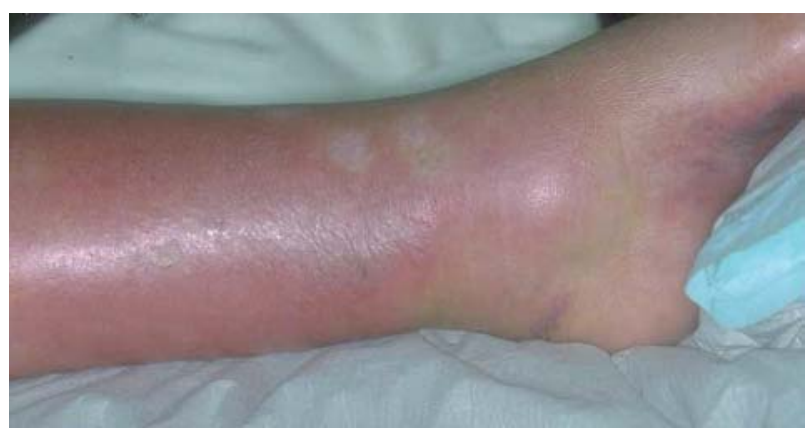

Figure 7 Cellulitis rash. Reproduced with permission from Dermatology Online Atlas (http://www.dermis.net).

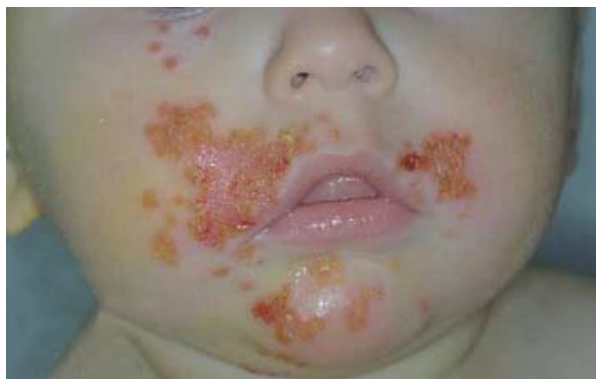

Figure 8 Rash resulting from impetigo. Reproduced with permission from Dermatology Online Atlas (http://www.dermis.net).

presentation. A red sore that oozes fluid or pus usually heralds the start of the infection. As the infection spreads, other lesions appear nearby that may be painful or itchy (see fig 8). The patient does not usually have a temperature but there may be swelling of the lymph glands nearby. Treatment has traditionally been with either topical or oral antibiotics. A recent meta-analysis highlighted the lack of a quality evidence base for the most effective treatment for impetigo. ${ }^{22}$ The authors concluded that the use of a topical antibiotic (such as mupirocin (Bactroban) or fucidic acid (Fucidin)) for seven days should be recommended in a patient with limited disease and no systemic upset. ${ }^{22}$ Oral antibiotics are reserved for more severe infections. The agents of choice are cephalexin, co-amoxiclav or erythromycin-all available in suspension form. ${ }^{23}$

\section{Scarlet fever}

- Management plan-4. Treat at home

This condition is associated with a bacterial infection of the throat caused by group A $\beta$ haemolytic streptococcus. It usually occurs in children under the age of 18. Symptoms include a sore throat, fever, swollen cervical glands, and a rash that usually lasts two to five days. This initially appears as tiny red bumps on the chest and abdomen before spreading all over the body. It has an appearance like sunburn with a rough feel (see figs 9 and 10). The diagnosis is confirmed by a throat swab, but treatment in the form of antibiotics (penicillin or erythromycin) is usually started on clinical grounds. Left untreated, complications such as nephritis or rheumatic fever can result.

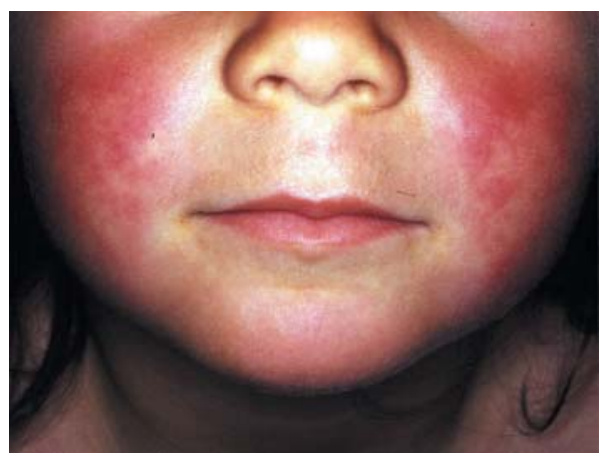

Figure 9 Rash on the face caused by scarlet fever. Reproduced with permission http://www.dermnetz.org. 


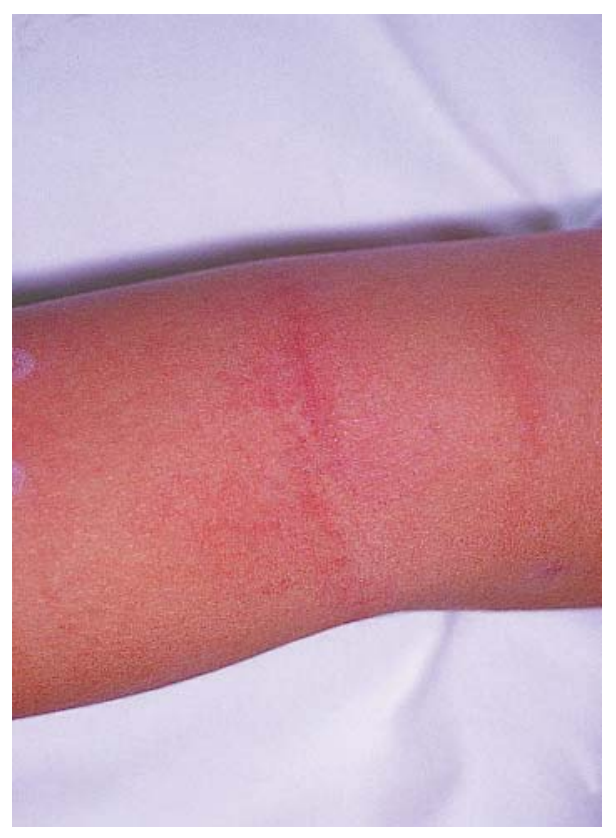

Figure 10 Scarlet fever rash. Reproduced with permission from Department of Health, Hong Kong.

\section{(2) Viral}

- Management plan-4. Treat at home

A rash is a clinical feature of many viral infections. Most are self limiting and require no specific treatments other than those aimed at reducing the associated symptoms, especially fever and itch. Some of the commoner infections to present (often with a rash) in the community are described in more detail below. Measles and rubella are notifiable diseases in the UK under the Public Health (Infectious Diseases) Regulations 1988; chickenpox is notifiable in Scotland only.

\section{Varicella zoster-chickenpox and shingles}

Varicella zoster presents as two clinical entities. Primary infection results in the rash known as chickenpox, a highly contagious illness, usually occurring in childhood outbreaks. The virus then lies dormant in nerve cells but may reactivate to cause herpes zoster, also known as "shingles". The risk of developing shingles increases with age and reduced immunocompetence (for example, immunosuppressive drugs, HIV infection, cancer).$^{24}$

\section{Chickenpox (notifiable in Scotland)}

In Scotland in 2001 there were 21894 notifications of chickenpox (428 per 100000 population, http://www.show. scot.nhs.uk/scieh accessed 28 Jul 2004). The classic symptoms of chickenpox are a rash, fever, and the general feeling of malaise seen with other viral infections. The rash usually appears within two weeks of exposure to the virus, with superficial spots that soon develop into blisters that burst and crust over (see fig 11). It is often intensely itchy and (a diagnostic pointer) spreads above the face and into the hair line. The rash remains a source of infection until all the blisters have crusted over. Chickenpox can spread to any person who has not been previously infected or vaccinated. Although in childhood it is usually a mild illness, it can

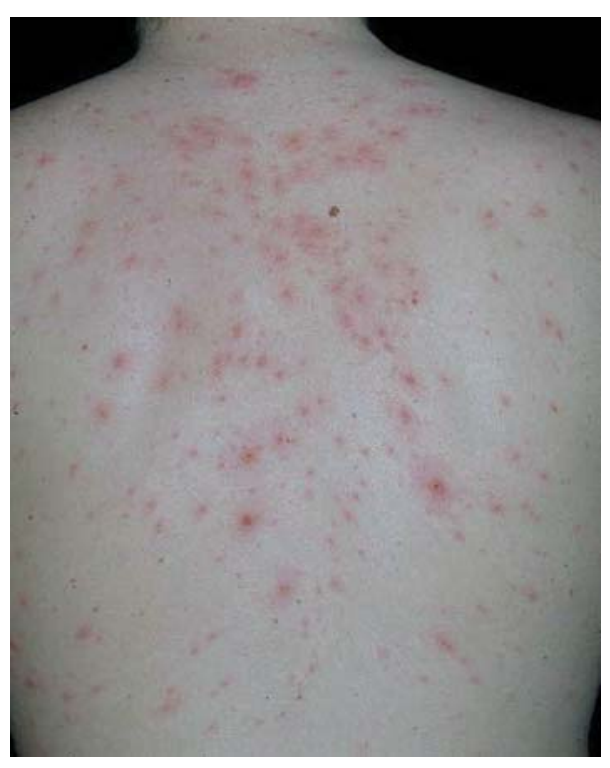

Figure 11 Rash caused by chickenpox. Reproduced with permission from Dermatology Online Atlas (http://www.dermis.net).

lead to complications including cellulitis, pneumonia, and encephalitis.

Chickenpox can also cause problems in pregnancymothers who have no immunity should avoid contact with people with the illness and seek urgent medical advice if contact has taken place. Specific immunoglobulin can be administered to reduce the likelihood of subsequent infection. In the absence of any complications, treatment is symptomatic and should focus on standard drugs for fever reduction, and antihistamines for associated itch. The affected person should be isolated from contact with the general public and family members with no personal history of chickenpox until the rash has completely crusted over.

\section{Shingles}

Initially, patients with shingles usually experience a nonspecific prodrome similar to that of other viral infections, followed by an area of abnormal skin sensation that may last one to five days before the appearance of the rash. Clusters of vesicles then appear that ultimately may ulcerate before crusting. The rash never crosses the midline and follows the line of one or more dermatomes (see figs 12 and 13). Pain of varying severity is present in virtually all patients. The rash heals in two to four weeks but may leave areas of scarring and changed pigmentation. In the acute phase, treatment entails the administration of appropriate analgesia. Initially this may take the form of paracetamol, with or without codeine (cocodamol). Resistant cases may require the use of adjuvant pain relief such as amitriptyline, gabapentin, or carbamazepine. Antiviral therapy in the form of acyclovir, valcyclovir, or famciclovir should be targeted towards those with the highest risk of complications-the immunocompromised, the elderly population, those with a large surface area involved, and those in severe pain at presentation. Use of these agents also reduces the incidence and severity of post-herpetic neuralgia ( $\mathrm{PHN}$ )—defined as pain that persists more than 30 days after the onset of the rash. 


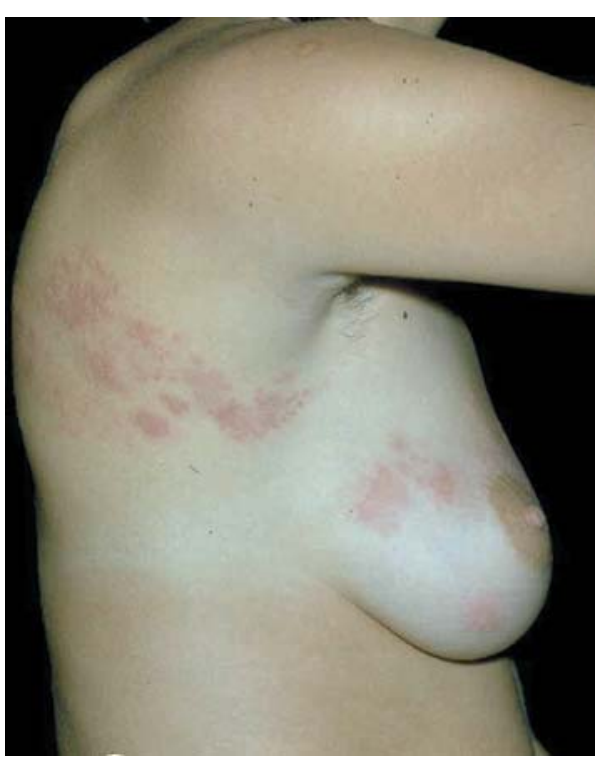

Figure 12 Illustration showing shingles of the chest. Reproduced with permission from Dermatology Online Atlas (http://www.dermis.net).

The incidence of PHN increases with age. Patients with a shingles rash on the forehead, around the eye or the nose have a $50 \%$ risk of developing severe eye complications. All such patients should be referred to an eye specialist immediately for assessment.

\section{Measles (notifiable)}

Measles is the most frequent cause of vaccine preventable deaths in childhood. ${ }^{25}$ It is primarily a viral respiratory tract infection, which can have serious or even fatal consequences for infants and small children. In 2003, there were 2488 cases notified to the Health Protection Agency. ${ }^{18}$ Protection is currently offered through the MMR vaccination. Unfortunately, since a link between this vaccine and the development of autism was suggested in 1998, ${ }^{26}$ reduced public confidence has resulted in a decreased uptake in vaccination, heralding the possibility of a major measles

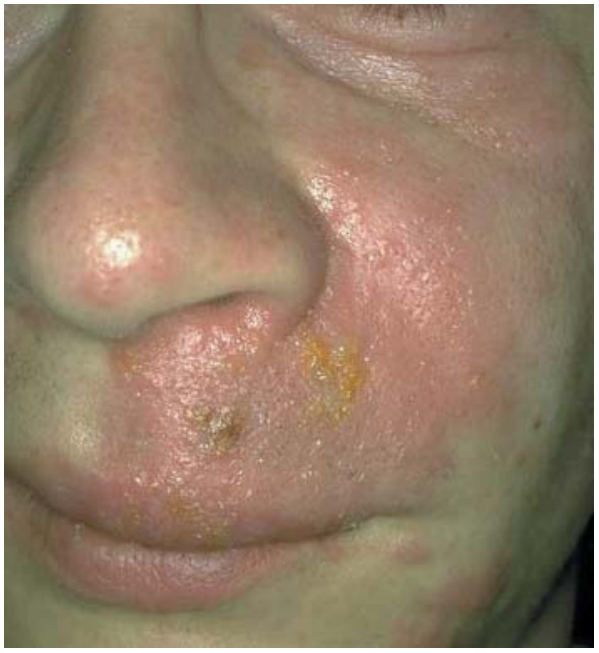

Figure 13 Shingles on the face. Reproduced with permission from Dermatology Online Atlas (http://www.dermis.net).

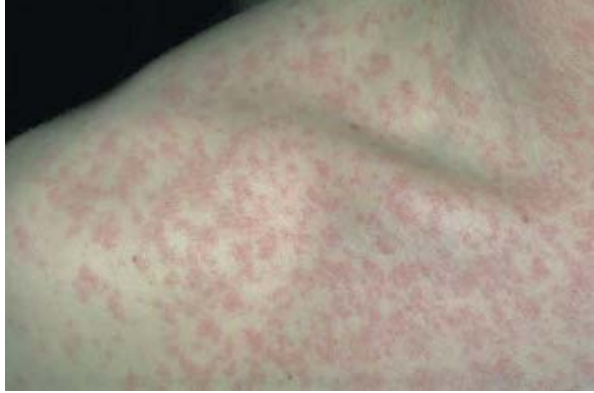

Figure 14 Measles rash. Reproduced with permission from Dermatology Online Atlas (http://www.dermis.net).

outbreak. While subsequent studies have conclusively shown no association and some of the authors of the original study have also conceded that MMR has no causal role, ${ }^{27}$ vaccine uptake remains as low as $61 \%$ in the UK.

Measles usually begins with a fever, a persistent cough, runny nose, and sore throat. Two or three days later, the characteristic Koplik's spots appear. These are tiny red spots on the inner mucosal lining of the cheek. Subsequently, the fever increases and a more generalised red blotchy rash develops on the face, along the hairline, and behind the ears. This slightly itchy rash rapidly spreads downward to the chest and back and, finally, to the thighs and feet (see fig 14). The rash tends to fade within seven days with the illness itself lasting 10-14 days. Measles is infectious from about four days before to four days after the rash appears. Complications include ear infections, pneumonia, encephalitis, and diarrhoea/vomiting. Non-immune pregnant women should seek specialist advice. Treatment is again largely symptomatic, and entails isolating the patient from the general public and susceptible family members.

\section{Rubella-German measles (notifiable)}

Although caused by a different virus, rubella shares some characteristics with measles (hence its synonym-"germanus" being Latin for similar). Rubella is neither as contagious nor as serious as measles, except that it can have serious consequences for the unborn child of an unprotected mother. Protection is again provided by the MMR vaccine, which has dramatically reduced the incidence of the condition. General symptoms, although milder, tend to be similar to measles but rarely last longer than three days. A fine, pink rash usually begins on the face and quickly spreads to the trunk and then the arms and legs before disappearing (see fig 15). Aching joints may occur, as may tender enlargement of the cervical lymph nodes. Rubella very rarely causes complications outwith pregnancy, where infection in the first trimester can lead to congenital abnormalities developing in up to $90 \%$ of cases. Symptomatic treatment and isolation are the only usual requirements for rubella.

\section{Non-specific viral rashes}

Virtually any viral infection can result in the development of a rash, usually on the face, chest, or back. The rash is usually very fine, red in colour, and blanches on pressure. It usually appears several days into the illness, often around the time the fever and other symptoms are improving. It may itch slightly but should not be painful. Care should be taken to exclude more serious causes of rashes (as outlined above). 


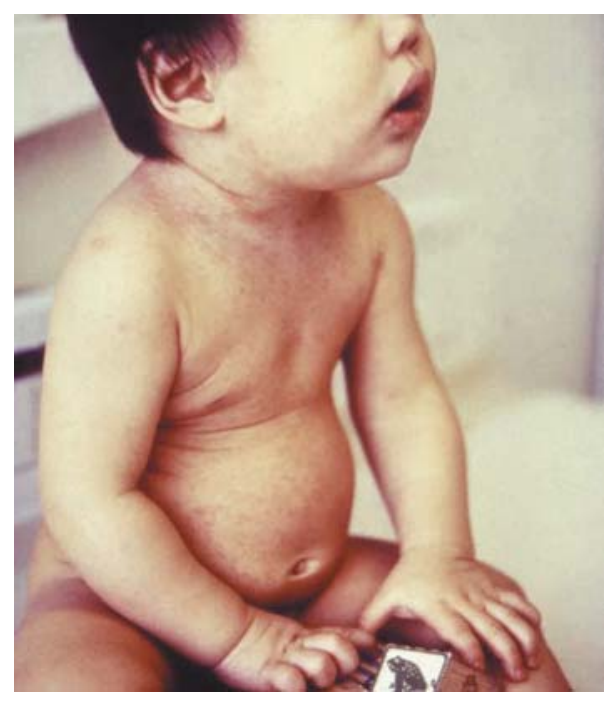

Figure 15 Rubella rash. Reproduced with permission from Dermatology Online Atlas (http://www.dermis.net).

The person affected may have symptoms such as a sore throat, runny nose, cough, or lethargy but has no symptoms of concern. The rash itself is not infectious and symptomatic treatment only is required.

\section{(3) Other conditions}

Henoch Schonlein purpura (HSP)

- Management plan 3. Seek further advice from hospital Like ITP, the importance of this condition is that it while it presents with a purpuric rash, it is not an acute life threatening condition. HSP classically affects children aged 3 to 8 years and is more common in boys. It often presents with a purpuric rash over the extensor surfaces of the buttocks and legs. Other common features are haematuria, proteinuria, and joint pains. The condition is largely self limiting although a small percentage of those affected may develop renal problems.

\section{Eczema and psoriasis}

- Management plan-4. Treat at home

Eczema and psoriasis are both chronic skin conditions that usually present in childhood and require treatment (albeit often intermittently) for life. This is usually started by the patient's GP, occasionally with input from a dermatologist. While both conditions can commonly adversely affect a patient's quality of life, they rarely lead to serious complications that might present to an out of hours practitioner with two notable exceptions:

\section{Infection}

Either condition may become infected, usually as a result of the patient scratching at itchy lesions. This then requires the use of either a topical or oral antibiotic in addition to any ongoing treatment. Appropriate therapy should be initiated as described earlier (see cellulitis).

\section{Pustular psoriasis}

- Management plan 3. Seek further advice from hospital Acute generalised pustular psoriasis is a rare but potentially life threatening complication of psoriasis, usually requiring inpatient hospital treatment. As its name suggests,

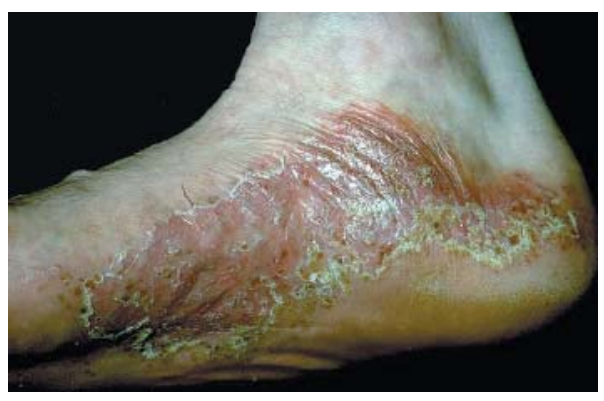

Figure 16 Pustular psoriasis affecting sole of the foot. Reproduced with permission from Dermatology Online Atlas (http:// www.dermis.net).

it presents in a patient with known psoriasis as widespread small pustules with areas of erythema, usually affecting the soles of the hands and/or feet (see fig 16). The pustules may coalesce to form large patches of pus. The condition may be precipitated by infection, pregnancy, or the withdrawal of corticosteroid therapy. If suspected, consultation with a dermatologist or medical registrar on call is advised.

\section{OTHER CAUSES OF ISOLATED ITCHING}

- Management plan-4. Treat at home

Itching in isolation may be the presenting feature of a wide range of other clinical conditions (table 7). All can be managed in the out hours setting by the use of basic symptomatic measures and the patient should be advised to seek medical assessment thereafter.

Basic symptomatic measures for the relief of itching Itching in isolation is often associated with dry skin, so a moisturiser should be applied. The skin should be kept cool and the patient advised to avoid alcohol and spicy foods. Shower and bath water should be kept tepid to avoid further irritation.

No universally effective drug or cream exists for the relief of itching. Antihistamine preparations in particular are only

\begin{tabular}{|c|c|}
\hline Cause & Comment \\
\hline Senile itch & $\begin{array}{l}\text { Occurs without an obvious cause in more } \\
\text { than } 50 \% \text { of those aged }>70 \text { years and is } \\
\text { thought to be linked to drying of the skin } \\
\text { with age' }\end{array}$ \\
\hline Cholestasis & Common symptom in jaundiced patients \\
\hline Uraemia & $\begin{array}{l}\text { Associated with chronic renal failure and } \\
\text { affects about } 25 \% \text { of those on haemodialysis. } \\
\text { It may be limited to the site of a haemodialysis } \\
\text { shunt. }\end{array}$ \\
\hline \multirow[t]{4}{*}{ Solid tumours } & $\begin{array}{l}\text { Specific tumours are associated with localised } \\
\text { itching- }\end{array}$ \\
\hline & - Scrotal itch with prostate cancer \\
\hline & Itchy nostrils with brain tumours \\
\hline & $\begin{array}{l}\text { Vulval itch with cervical cancer } \\
\text { Itch may also complicate chemotherapy }\end{array}$ \\
\hline Blood disorders & $\begin{array}{l}\text { Itch is frequently associated with disorders } \\
\text { such as Hodgkin's lymphoma, leukaemia, } \\
\text { myeloma, and polycythaemia. It may also } \\
\text { occur with iron deficiency anaemia }\end{array}$ \\
\hline HIV & $\begin{array}{l}\text { Itch is sometimes the first symptom of HIV related } \\
\text { disease }\end{array}$ \\
\hline
\end{tabular}


effective for itching caused by the release of histamine (for example, insect bites). Creams containing a $1 \%-2 \%$ mixture of menthol or phenol with aqueous cream can be applied topically several times a day for symptomatic relief of itching.

\section{FORMULATING A SAFE AND EFFECTIVE} MANAGEMENT PLAN

Assess the patient's symptoms and signs to decide whether your patient needs emergency admission, semi-urgent admission, or whether they can be safely treated at home:

\section{Admit and treat immediately as an emergency (features of concern) \\ Signs}

- Signs of airway obstruction

- Respiratory rate $<10$ or $>29$

- Oxygen saturation $<92 \%$ on air

- Pulse rate $<50$ or $>120$

- Systolic $\mathrm{BP}<90$

- Glasgow coma score $<12$

\section{Symptoms}

- Suspected rash of meningococcal septicaemia

- Definite exposure to a trigger that has previously lead to an anaphylactic reaction

- Self administration of adrenaline by a patient for a suspected anaphylactic reaction

- A suspected anaphylactic reaction that has not fully developed

\section{Admit as a semi-urgent case to hospital for further assessment and treatment}

- Suspected cellulitis

- Affecting the eyes or tissues around the eyes

- Patient is "unwell' (that is, raised temperature, rigors, vomiting)

- Patient unable to take oral antibiotics

- No discernable clinical response to 24 hours of appropriate oral antibiotics

- Other features of concern - for example, considerable pain or swelling, adverse social circumstances (lives alone, family unable to cope, etc)

\section{Advisable to seek further advice from hospital}

- Purpuric rash but patient appears clinically well

- Possible ITP or HSP

- Possible pustular psoriasis

\section{Can be treated at home, assuming no features of concern (as above)}

- Local allergic reactions

- Urticaria/angioedema

- Bacterial infections-mild cellulitis, impetigo, scarlet fever

- Viral infections - chickenpox ${ }^{* \ddagger}$, shingles, ${ }^{*}$ measles ${ }^{*}+$, rubella ${ }^{*} \neq$, non-specific viral rashes

- ${ }^{*}$ Requires isolation to avoid spread (see text)

- ${ }^{\dagger}$ Notifiable disease in England and Wales (see text)

_ ${ }^{\ddagger}$ Notifiable disease in Scotland (see text)

\section{椡 Pitfall}

Although this list aims to guide appropriate management, it is not foolproof. If in doubt, seek further medical advice.

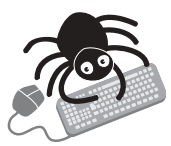

Flow charts for the diagnosis and management of allergy and rash are available on the journal web site (http://www.emjonline.com/supplemental).

\section{Authors' affiliations}

M Langran, Aviemore Health Centre, Muirton, Aviemore, UK

C Laird, BASICS Scotland, Auchterarder, UK

\section{USEFUL ONLINE RESOURCES}

Health Protection Agency (http://www.hpa.org.uk)

Scottish Centre for Infection and Environmental Health (http://www.show.scot.nhs.uk/scieh)

Anaphylaxis Canada (http://www.anaphylaxis.org)

UK based anaphylaxis campaign (http://www.anaphylaxis. org.uk/)

Meningitis Research Foundation (UK) (http://www.meningitis. org.uk)

British Association of Dermatologists (UK) (http://www.bad. org.uk/about/)

Medic Alert Foundation (UK) (http://www.medicalert.co.uk) Allergy UK (UK) (http://www.allergyuk.org)

American Academy of Allergy, Asthma and Immunology (http://www.aaaai.org)

Food Allergy and Anaphylaxis Network (http://www. foodallergy.org/index.html)

World Allergy Organisation-list of worldwide allergy links (http://www.worldallergy.org/links.shtml)

Platelet Disorder Support Association-comprehensive web resource on ITP (http://www.pdsa.org/)

\section{REFERENCES}

1 Twycross R, Greaves MW, Handwerker $\mathrm{H}$, et al. Itch: scratching more than the surface. QJM 2003;96:17-26.

2 Woodward CM, Jessop EG, Wale MC. Early management of meningococcal disease. Commun Dis Rep CDR Rev 1995:5:R135-7.

3 Mclean-Tooke AP, Bethune CA, Fay AC, et al. Adrenaline in the treatment of anaphylaxis: what is the evidence? BMJ 2003;327:1332-5

4 Brown AF, McKinnon D, Chu K. Emergency department anaphylaxis: a review of 142 patients in a single year. J Allergy Clin Immunol $2001 ; 108: 861-6$

5 Kemp SF, Lockey RF, Wolf BL, et al. Anaphylaxis. A review of 266 cases. Arch Intern Med 1995; 155:1749-54.

6 Noone MC, Osguthorpe JD. Anaphylaxis otolaryngol. Clin North Am 2003;36:1009-20.

7 Simons FER, Chad Z, Gold M. Real-time reporting of anaphylaxis in infants, children and adolescents by physicians involved in the Canadian Pediatric Surveillance Program. J Allergy Clin Immunol 2002;109:S181.

8 Gupta R, Sheikh A, Strachan D, et al. Increasing hospital admissions for systemic allergic disorders in England: analysis of national admissions data. BMJ 2003:327:1142-3.

9 Simons FE, Gu X, Simons KJ. Epinephrine absorption in adults: intramuscular versus subcutaneous injection. J Allergy Clin Immunol $2001 ; 108: 871-3$

10 Tang AW. A practical guide to anaphylaxis. Am Fam Physician 2003;68:1325-32

11 Lieberman P. The use of antihistamines in the prevention and treatment of anaphylaxis and anaphylactoid reactions. J Allergy Clin Immunol 1990:86:684-6.

12 Stark BJ, Sullivan TJ. Biphasic and protracted anaphylaxis. J Allergy Clin Immunol 1986;78:76-83.

13 Ellis AK, Day JH. Diagnosis and management of anaphylaxis. Can Med Assoc J 2003; 169:307-11.

14 Hogan C. Anaphylaxis. The GP perspective. Aust Fam Physician 2002;31:807-9. 
15 British Association of Dermatologists. Urticaria and angioedema. http:// www.bad.org.uk/patients/disease (accessed 17 Mar 2004).

16 Grattan C, Powell S, Humphreys F. Management and diagnostic guidelines for urticaria and angio-oedema. $\mathrm{Br} J$ Dermatol 2001;144:708-14.

17 Fay $A$, Abinun M. Current management of hereditary angio-oedema $\left(C^{\prime}\right]$ esterase inhibitor deficiency). J Clin Pathol 2002;55:266-70.

18 Health Protection Agency. NOIDs annual totals 1991-2002. http:// www.hpa.org.uk/infections/topics_az/noids/annualtab.htm (accessed 17 Mar 2004).

19 Surtees SJ, Stockton MG, Gietzen TW. Allergy to penicillin: fable or fact? BMJ 1991;302:1051-2.

20 Begg N, Cartwright KA, Cohen J, et al. Consensus statement on diagnosis, investigation, treatment and prevention of acute bacterial meningitis in immunocompetent adults. British Infection Society Working Party. J Infect 1999;39:1-15.
21 Baxter $\mathrm{H}, \mathrm{McG}$ Gegor F. Understanding and managing cellulites. Nurs Stand 2001;15:50-6.

22 George A, Rubin G. A systematic review and meta-analysis of treatments for impetigo. Br J Gen Pract 2003;53:480-7.

23 Hedrick J. Acute bacterial skin infections in pediatric medicine: current issues in presentation and treatment. Paediatr Drugs 2003;5(suppl 1):35-46.

24 Gnann JW Jr, Whitley RJ. Clinical practice. Herpes zoster. N Engl J Med 2002;347:340-6.

25 Duke T, Mgone CS. Measles: not just another viral exanthema. Lancet 2003;361:763-73.

26 Wakefield AJ, Murch SH, Anthony A, et al. Ileal-lymphoid-nodular hyperplasia, non-specific colitis, and pervasive developmental disorder in children. Lancet 1998;351:637-41.

27 Murch S. Separating inflammation from speculation in autism. Lancet 2003;362:1498-9. 